\title{
Soluble Urokinase-type Plasminogen Activator Receptor Predicts All-cause 5-Year Mortality in Ischemic Stroke and TIA
}

\author{
JUHA ONATSU ${ }^{1}$, MIKKO TAINA ${ }^{2}$, PIRJO MUSTONEN ${ }^{3}$, MARJA HEDMAN ${ }^{2}$, \\ ANTTI MUURONEN ${ }^{2}$, OTSO ARPONEN ${ }^{2}$, MIIKA KORHONEN ${ }^{2}$, \\ PEKKA JÄKÄLÄ ${ }^{1,4}$, RITVA VANNINEN ${ }^{2,5}$ and KARI PULKKI ${ }^{6,7}$ \\ ${ }^{1}$ Department of Neurology, NeuroCenter, and ${ }^{2}$ Department of Clinical Radiology, \\ Kuopio University Hospital, Kuopio, Finland; \\ ${ }^{3}$ Department of Cardiology, Keski-Suomi Central Hospital, Jyväskylä, Finland; \\ ${ }^{4}$ Unit of Neurology, Institute of Clinical Medicine and Departments of ${ }^{5}$ Clinical Radiology and \\ ${ }^{6}$ Clinical Chemistry, University of Eastern Finland, Kuopio, Finland; \\ ${ }^{7}$ Eastern Finland Laboratory Centre, Kuopio, Finland
}

\begin{abstract}
Aim: We evaluated soluble urokinase-type plasminogen activator receptor (suPAR) levels in different stroke subtypes and assessed their prognostic value regarding 5-year outcomes. Materials and Methods: The study included 117 stroke patients (81 males; mean=age $61 \pm 11$ years) with suspected cardioembolic stroke whose plasma suPAR concentration was assessed. Altogether, 20 (17.1\%) patients suffered from stroke as a result of cardioembolism, 12 (10.3\%) from large-artery atherosclerosis, 9 (7.7\%) from small-vessel disease, 11 (9.4\%) from both large-artery and cardioembolic etiology, and $65(55.6 \%)$ had cryptogenic stroke. The mean followup period was 5 years. Results: SUPAR concentration was higher in patients who suffered from strokeltransient ischemic attack due to large-artery atherosclerosis $(3.2 \pm 0.9 \mathrm{ng} / \mathrm{ml})$ compared to small-vessel disease $(2.0 \pm 0.5$ $n g / m l, p<0.001)$. An elevated plasma suPAR concentration was associated with all-cause mortality during the followup period ( $p=0.003$ ). Conclusion: Elevated plasma suPAR concentrations predicted all-cause mortality during the 5year follow-up after ischemic stroke. suPAR was not able to differentiate patients with cardioembolic stroke from those with other stroke types.
\end{abstract}

This article is freely accessible online.

Correspondence to: Juha Onatsu, MD, Department of Neurology, NeuroCenter, Kuopio University Hospital, P. O. BOX 100, 70029 Kuopio, Finland. Tel: +358 447174856, e-mail: Juha.Onatsu@kuh.fi

Key Words: suPAR, ischemic stroke, inflammation, mortality, cardioembolic.
The precise etiological evaluation of stroke subtype is crucial as approximately $20-25 \%$ of all strokes recur and the risk of recurrence can be reduced with prompt and appropriate secondary prevention $(1,2)$. There are currently several mechanisms recognized as underlying ischemic strokes and transient ischemic attacks (TIAs), namely embolism, thrombosis or decreased systemic hypoperfusion $(3,4)$. Emboli reaching the brain can originate from the heart, cervical arteries or aorta and also from veins, constituting paradoxical embolism. Most non-lacunar ischemic strokes are considered to be embolic (5-7).

Low-grade inflammation plays a crucial role in vascular atherosclerosis, which is the principal cause behind arterial thrombosis (8). Inflammation is also known to be a major contributor to stroke pathophysiology (9). High levels of many inflammatory biomarkers [e.g. high-sensitive CRP (hsCRP) and several proinflammatory cytokines] have been associated with poor functional outcome after stroke (10).

In the presence of either acute or chronic inflammation, membrane-bound urokinase-type plasminogen activator receptor (UPAR) becomes cleaved from the cell surface and released into the circulation, forming soluble uPAR (suPAR) (11-13) providing a novel marker of both chronic inflammation and poor prognosis (14). Elevated levels of suPAR in plasma and carotid plaque have been associated with TIA and stroke (15). There is a report that patients with ischemic stroke express higher levels of suPAR compared to patients with amaurosis fugax (16).

At present, little is known about suPAR levels in different cohorts of patients with ischemic stroke. The aim of this prospective 5-year follow-up study was to examine suPAR levels and their associations with subtypes of ischemic stroke and to furthermore assess their possible prognostic value with respect to the 5-year outcome. 


\section{Materials and Methods}

This 5-year follow-up study is part of the EmbodeteCT study (1719). Between March 2005 and November 2009, patients admitted to our university hospital because of acute stroke/TIA with suspected cardioembolic etiology but without known atrial fibrillation (AF) were evaluated as study candidates. Exclusion criteria were symptoms indicating large-artery atherosclerosis, small-vessel occlusion and hypercoagulable states (Figure 1). The study was approved by the University Hospital Research Ethics Board (no. 82/ 2004) and written informed consent was obtained from the participants or their legally authorized representatives. After a 5-year follow-up period from the index stroke/TIA episode, patient files from primary, secondary and tertiary levels of the healthcare system were used to gather information about the follow-up endpoints: a) stroke/TIA recurrence, b) myocardial infarction (MI), c) AF or other signs of systemic embolism, and d) death. The causes of death were gathered from death certificates held by Statistics Finland.

In an extension to the routine imaging protocol, a combined examination of the heart, aorta, and cervicocranial arteries with computed tomography together with transthoracic and transesophageal echocardiography were performed to define the etiology of stroke (18). For volume measurements of infarcted cerebral tissue, 4.5-5 $\mathrm{mm}$ transversal slices were reconstructed in brain computed tomography in the subacute phase ( $>2$ days). Infarction volume was calculated by using Simpson's method (20). Ambulatory 24-hour Holter was performed to evaluate the presence of paroxysmal AF. Etiological classification was based on TOAST criteria (21), modified by the more recent recommendations from the Association of Echocardiography for defining the cardiac source of embolism (22). Blood samples for suPAR and hsCRP were collected at study enrollment and 3 months later. Blood was collected in $3.2 \%$ sodium citrate, plasma was separated by centrifugation at $2500 \times g$ and stored at $-80^{\circ} \mathrm{C}$ until analyzed. suPAR concentrations were measured using the commercial ELISA suPARnostic kit (ViroGates, Copenhagen, Denmark) and hsCRP was analyzed using standard procedures at the Department of Clinical Chemistry, Kuopio University Hospital. The calculated concentrations were corrected with the dilution factor as a result of use of sodium citrate solution.

Continuous variables with normal distributions are presented as the mean $\pm \mathrm{SD}$, and categorical variables as absolute values and percentages. Based on the results of Kolmogorov-Smirnov test, Student's $t$-test was applied for normally distributed values and Mann-Whitney $U$-test used for abnormally distributed nonparametric values when comparing dichotomized groups. Pairedsamples $t$-test was used to compare acute and plateau phase concentrations. Spearman's correlation coefficient was used to investigate the associations between continuous background characteristics and the plasma suPAR concentration. Chi-square test was used to investigate nominal variables. Statistical significance was set at $p<0.05$ and high statistical significance at $p<0.01$. The predictive value of suPAR for all-cause mortality was assessed with Cox regression model where covariates were entered using a backward Wald's model. In addition to an elevated plasma suPAR concentration (of $>1 \mathrm{ng} / \mathrm{ml}$ ), the following covariates were selected based on the literature: age, gender, body-mass index (BMI), tobacco use, previous MI, diagnosed hypertension, hypercholesterolemia, diabetes, National Institutes of Health Stroke Scale (NIHSS) and AF. Data were analyzed using SPSS for Mac (version 22; IBM Corp., Armonk, NY, USA).

\section{Consecutive patients with acute ischemic stroke/TIA} between March 2005 and November $2009(n=3069)$

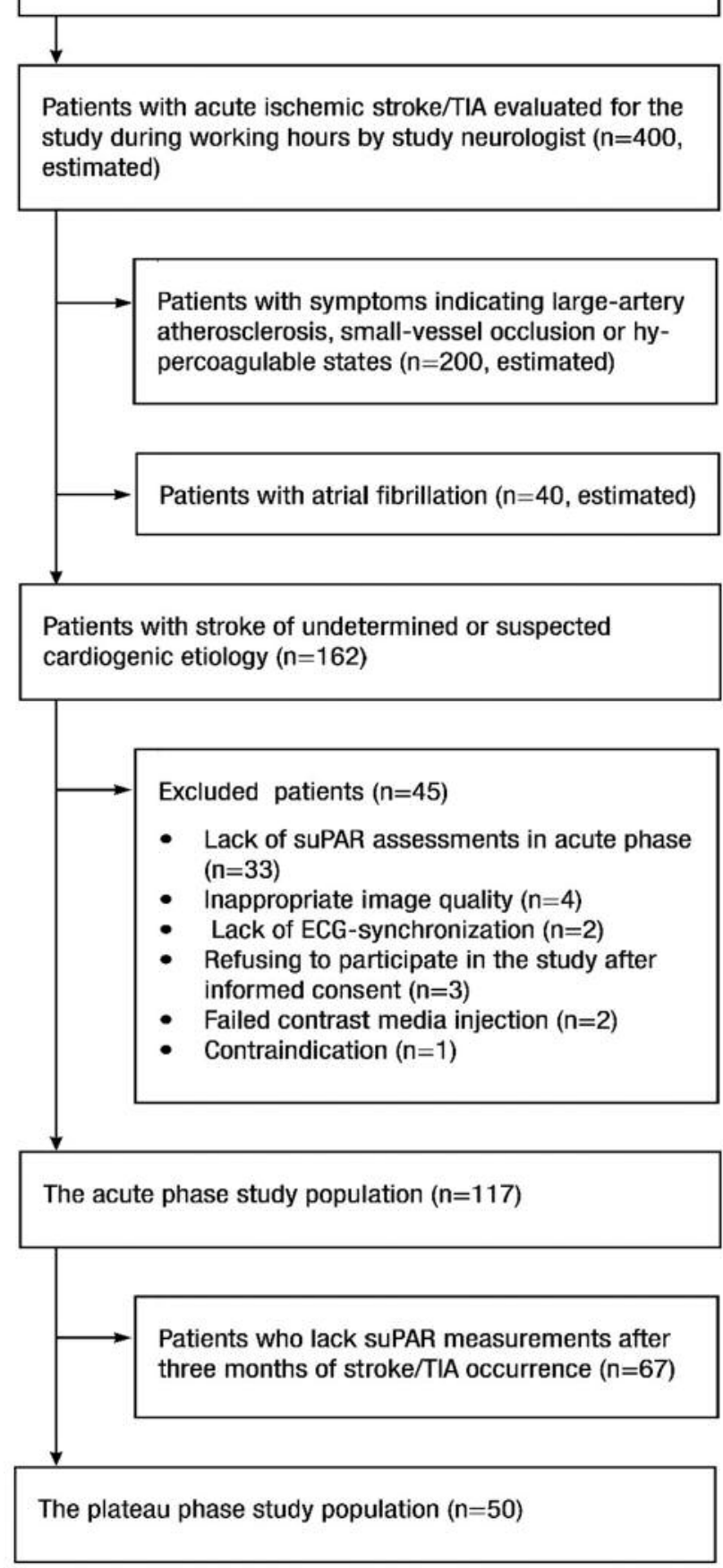

Figure 1. Flow chart of patient recruitment.

\section{Results}

suPAR concentrations were measured in a total of 117 patients (81 males; mean=age $61 \pm 11$ years; range $=32-84$ years) during the diagnostic evaluation of acute stroke/TIA (acute phase) 
Table I. Clinical characteristics of the study population.

\begin{tabular}{|c|c|c|c|c|}
\hline \multirow[b]{2}{*}{ Characteristic } & \multicolumn{2}{|c|}{$\begin{array}{l}\text { Patients with suPAR measurement } \\
\text { during stroke occurrence }\end{array}$} & \multicolumn{2}{|c|}{$\begin{array}{l}\text { Patients with suPAR measurement after } \\
3 \text { months of stroke occurrence }\end{array}$} \\
\hline & $\mathrm{N}$ & Value & $\mathrm{N}$ & Value \\
\hline Male gender, $\mathrm{n}(\%)$ & 117 & $81(69.2)$ & 50 & $34(68.0)$ \\
\hline Age, years & 117 & $61.3 \pm 10.6$ & 50 & $60.8 \pm 11.0$ \\
\hline Body mass index, $\mathrm{kg} / \mathrm{m} 2$ & 117 & $28.1 \pm 4.3$ & 50 & $27.9 \pm 4.3$ \\
\hline Hypertension, $\mathrm{n}(\%)$ & 117 & $70(59.8)$ & 50 & $25(50.0)$ \\
\hline Diabetes, $\mathrm{n}(\%)$ & 117 & $16(13.7)$ & 50 & $2(4.0)$ \\
\hline Smokers, n (\%) & 117 & $28(23.9)$ & 50 & $11(22.0)$ \\
\hline Prior stroke, $\mathrm{n}(\%)$ & 117 & $21(17.9)$ & 50 & $8(16.0)$ \\
\hline Prior myocardial infarction, $\mathrm{n}(\%)$ & 117 & $16(13.7)$ & 50 & $8(16.0)$ \\
\hline VAT & 83 & $186.3 \pm(85.6)$ & 39 & $183.8 \pm 98.1$ \\
\hline hsCRP & 114 & $7.1 \pm(18.7)$ & 50 & $4.4 \pm 10.2$ \\
\hline \multicolumn{5}{|l|}{ Medication, n (\%) } \\
\hline Aspirin & 117 & $36(31.0)$ & 50 & $19(38.0)$ \\
\hline Warfarin & 117 & $10(8.5)$ & 50 & $4(8.0)$ \\
\hline Clopidogrel & 117 & $3(2.6)$ & 50 & $1(2.0)$ \\
\hline Dipyridamole & 117 & $7(6.0)$ & 50 & $2(4.0)$ \\
\hline Statin & 117 & $36(30.8)$ & 50 & $15(30.0)$ \\
\hline \multicolumn{5}{|l|}{ Cholesterol, mmol/1 } \\
\hline Total cholesterol & 115 & $4.5 \pm 1.0$ & 49 & $4.6 \pm 1.1$ \\
\hline Low-density lipoprotein & 115 & $2.8 \pm 0.9$ & 49 & $2.9 \pm 0.9$ \\
\hline
\end{tabular}

VAT: Visceral adipose tissue (19), hsCRP: high sensitive C-reactive protein, suPAR: soluble urokinase plasminogen activator receptor.

Table II. Plasma soluble urokinase plasminogen activator receptor (suPAR) concentration (ng/ml) according to stroke etiology. There were no statistically significant differences in the acute-phase plasma suPAR concentration of other groups when compared with patients with cardioembolic stroke.

\begin{tabular}{lccccc}
\hline Etiology & $\mathrm{N}(\%)$ & $\begin{array}{c}\text { Acute-phase suPAR } \\
\text { mean } \pm \text { SD (N=117) }\end{array}$ & $\begin{array}{c}\text { Plateau-phase suPAR } \\
\text { mean } \pm \text { SD (N=50) }\end{array}$ & $\begin{array}{c}p \text {-Value* } \\
\text { Mortality, N (\%) of } \\
\text { all deaths (N=14) }\end{array}$ \\
\hline Cardioembolism & $20(17.1)$ & $2.5 \pm 0.7$ & $2.8 \pm 0.3$ & $\mathrm{~ns}$ & $4(28.6 \%)$ \\
Large-artery atherosclerosis & $12(10.3)$ & $3.2 \pm 0.9$ & $4.2 \pm 1.6$ & $2.6<0.001$ & $4(28.6 \%)$ \\
Small-vessel disease & $9(7.7)$ & $2.0 \pm 0.5$ & $2.2 \pm 0.3$ & $\mathrm{~ns}$ & $1(7.1 \%)$ \\
Both large-artery and cardioembolic & $11(9.4)$ & $2.9 \pm 0.7$ & $2.6 \pm 0.5$ & $\mathrm{~ns}$ & $4(28.6 \%)$ \\
Cryptogenic & $65(55.6)$ & $2.7 \pm 1.5$ & $2.6 \pm 1.0$ & $\mathrm{~ns}$ & \\
\hline
\end{tabular}

*For difference in the acute-phase plasma suPAR concentration when compared with patients with large-artery atherosclerosis stroke. There were no statistically significant differences in the acute-phase plasma suPAR concentration of other groups when compared with patients with cardioembolic stroke. ns: Non significant.

and these were repeated three months later in $50(43 \%)$ patients (plateau phase). There was no statistically significant difference in plasma suPAR concentrations between the acute and plateau phases. Patient characteristics of both phases are presented in Table I.

Twenty (17\%) patients were considered to have suffered a cardioembolic stroke/TIA. Their plasma suPAR concentration did not differ significantly from those who suffered stroke/TIA with a non-cardioembolic etiology either in acute or plateau phase (Table II). However, in patients who suffered stroke/TIA due to large-artery atherosclerosis $(n=12)$ the acute phase suPAR concentration $(3.2 \pm 0.9 \mathrm{ng} / \mathrm{ml})$ was significantly higher than the corresponding value in patients who suffered stroke/TIA due to small-vessel disease $(\mathrm{n}=9 ; 2.0 \pm 0.5 \mathrm{ng} / \mathrm{ml}$, $p<0.001$ ) (Figure 2). No significant differences were observed between the other etiological groups.

suPAR levels did not differ between patients with stroke vs. those with TIA, whereas patients in acute phase of stroke displayed higher levels of hsCRP than patients with TIA $(p=0.045)$. Neither suPAR nor hsCRP levels correlated with 
infarct volumes as measured by non-contrast brain computed tomography. Ten patients $(8.5 \%)$ were treated with recombinant tissue plasminogen activator. The suPAR levels of this small group did not differ from those of the others $(p=0.6)$. Other anti-aggregatory or anticoagulative drugs, e.g. acetylsalicylic acid, dipyridamole, clopidogrel or warfarin, had no significant effect on suPAR level $(p>0.1)$.

During the 5-year follow-up, no association was found between the acute-phase plasma suPAR concentration and frequency of stroke/TIA recurrence or MI; however, a higher acute-phase plasma suPAR concentration was strongly associated with all-cause mortality. Thus, the acute-phase plasma suPAR concentration was $3.5 \pm 1.4 \mathrm{ng} / \mathrm{ml}$ in patients who died $(\mathrm{n}=14 ; 12 \%)$, whereas the concentration was $2.6 \pm 1.2$ $\mathrm{ng} / \mathrm{ml}$ in the other patients $(\mathrm{n}=103 ; 88 \%, p=0.003)$. Plateauphase concentrations did not, however, differ between patients who died $(\mathrm{n}=6 ; 3.6 \pm 1.6 \mathrm{ng} / \mathrm{ml})$ and those who survived $(\mathrm{n}=44$, $2.6 \pm 0.9 \mathrm{ng} / \mathrm{ml})$. Based on Cox regression analysis, a continuously elevated level of suPAR had a hazard ratio of 1.60 (95\% confidence interval=1.10-2.30, $p=0.012$ ) for death during the 5-year follow-up. Kaplan-Meier survival analysis showed that there was a significant difference in all-cause mortality between patients with higher or lower suPAR consentrations (suPAR concentration over or less than $3 \mathrm{ng} / \mathrm{ml})(p=0.014)$.

\section{Discussion}

To our knowledge, this is the first study which has analyzed suPAR levels in stroke/TIA cohorts with different etiologies. We found that the suPAR level was not able to differentiate cardioembolic etiology of stroke/TIA from atherosclerotic etiologies. The acute-phase suPAR concentration was significantly higher in patients who suffered stroke due to large-artery atherosclerosis compared to those who had small-vessel disease. Furthermore, elevated levels of suPAR were significantly associated with all-cause mortality in the 5-year follow-up.

The regulation and formation of suPAR are not completely understood, but it is believed that suPAR negatively regulates the proteolytic activity of uPA, an important activator of plasminogen (23). In the presence of acute or chronic inflammation,such as encountered in several pathological conditions, e.g. infections, various tumors and in cardiovascular diseases (CVD), the membrane-bound uPAR is cleaved from the cell surface and released into the circulation. suPAR has been shown to outperform hsCRP, another marker of inflammation, in the prognosis of several CVDs $(13,24,25)$, but the diagnostic value of suPAR is considered to be low $(26,27)$. New evidence also suggests that suPAR indicates different pathophysiological pathways than hsCRP in atherosclerosis (28). An earlier populationbased study by Persson et al. suggested that plasma suPAR levels are higher in asymptomatic individuals with carotid

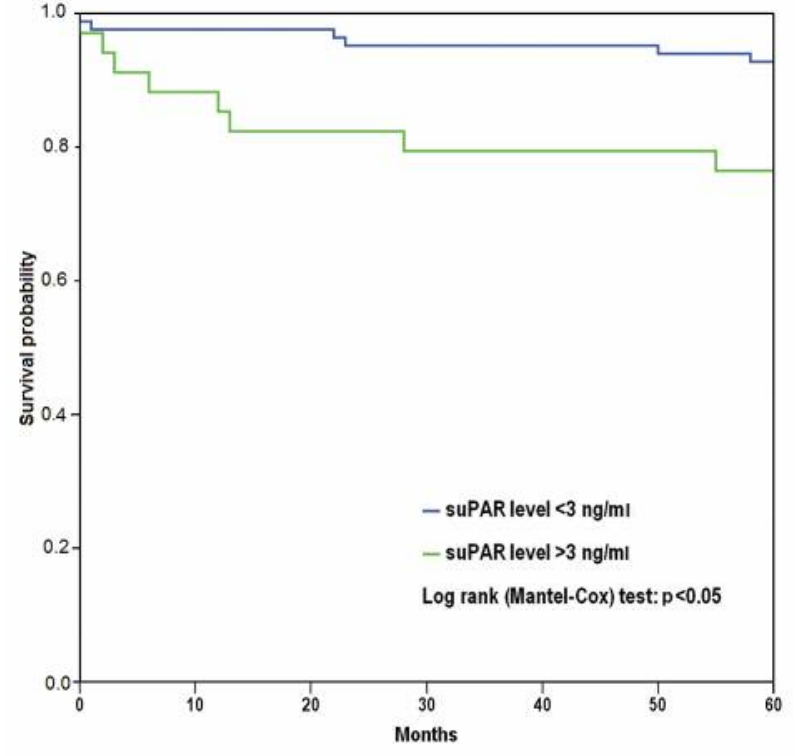

Figure 2. Kaplan-Meier plot for all-cause mortality for soluble urokinase plasminogen activator receptor (suPAR) concentration. Patients with higher $(>3 \mathrm{ng} / \mathrm{ml})$ suPAR levels had higher probability for all-cause mortality $(p<0.05)$ during the 5-year followup period.

plaques in comparison to those without plaques. Moreover, a high suPAR level significantly increased the risk of ischemic stroke in patients with carotid plaques during a mean follow-up of 15 years (29).

One could speculate that if suPAR is strongly associated with atherosclerosis, then perhaps the determination of the plasma suPAR concentration could help to elucidate the mechanisms behind acute stroke. Not surprisingly, the present study revealed that patients with stroke/TIA with large-artery atherosclerotic etiology had the highest suPAR levels compared to those in patients with other etiologies. However, this difference was statistically significant only in comparison to the group with small-vessel disease. This can be explained by pathogenesis: lipohyalinosis and fibrinoid necrosis, but not atherosclerosis, are the underlying mechanisms in small-vessel disease (30), whereas low-grade inflammation has a key role in atherosclerosis.

Recently, an association was reported between an increased plasma suPAR concentration and the incidence of venous thromboembolism (VTE) (deep venous thrombosis and pulmonary embolism), thus suPAR was also proposed to be a risk indicator for thrombus formation (31). This is in contrast to our study, where the suPAR concentration was low to moderate in patients with cardioembolic stroke. Theoretically, suPAR could be related to thrombus formation by competing with membrane-bound UPAR, thereby reducing the uPA fibrinolytic activity. A reduction in uPA activity could correlate with an increased risk for thrombus formation 
and a higher incidence of embolism in patients with high suPAR levels (31).

Even though elevated baseline plasma levels of suPAR were significantly associated with all-cause mortality, we did not detect any significant association between suPAR level and stroke recurrence or MI during the 5-year follow-up. This is in contrast to a previous study reporting strong correlations between elevated suPAR level and recurrent MI in patients with suspected or known coronary artery disease (32). The present study examined stroke patients instead of MI patients and known large-artery atherosclerosis was an exclusion criteria in our study, which may explain the contrasting results. In our study, neither suPAR nor hsCRP levels correlated with the volume of infarction measured from brain computed tomography. We found no association between the incidence of AF and the suPAR levels during the 5-year follow-up, although an inflammatory mechanism has been suggested to be a pathogenic factor behind atrial arrhythmias $(33,34)$. The causal relationship between suPAR and all-cause mortality remains to be clarified.

In addition to its associations to atherosclerosis, suPAR has also been shown to be a good prognostic marker of in-hospital mortality in patients suffering severe infection and septic shock (35), as well as being a prognostic marker in cardiovascular mortality in a black South African population (36) and various other settings $(24,36)$. Interestingly, in a study of 60 patients undergoing coronary artery bypass surgery, perioperative levels of suPAR remained stable despite the extensive inflammatory reaction induced by such major surgery (37). Likewise, in patients with ST elevation MI undergoing primary percutaneous coronary angioplasty, suPAR levels remained unchanged even when hsCRP levels were considerably elevated (38). There are several previous studies suggesting that suPAR and hsCRP are produced by different inflammatory pathways. Accordingly in our study, patients in the acute phase of stroke had significantly higher hsCRP levels than patients with TIA but no such difference was found in suPAR levels.

\section{Limitations}

Primarily the EmbodeteCT study focused on patients with suspected cardioembolic stroke/TIA and excluded patients with known AF. Exclusion criteria were also symptoms indicating large-artery atherosclerosis, small-vessel occlusion and hypercoagulable states; hence the study included only a small subpopulation of all patients with stroke/TIA. This reduces generalizability of these results to all patients with stroke.

To conclude, in our study, an elevated plasma suPAR concentration predicted all-cause mortality during a 5-year follow-up after ischemic stroke. However, suPAR was not suitable for screening patients with cardioembolic etiology of stroke. We propose that future studies should focus on suPAR and inflammatory mechanisms in stroke patients.

\section{Conflicts of Interest}

The Authors have stated that they have no conflict of interest in regard to this study.

\section{Acknowledgements}

The Authors thank Tuomas Selander for his assistance regarding Cox regression analyses.

\section{References}

1 Rothwell PM, Giles MF, Chandratheva A, Marquardt L, Geraghty O, Redgrave JN, Lovelock CE, Binney LE, Bull LM, Cuthbertson FC, Welch SJ, Bosch S, Alexander FC, Silver LE, Gutnikov SA and Mehta Z: Effect of urgent treatment of transient ischaemic attack and minor stroke on early recurrent stroke (EXPRESS study): a prospective population-based sequential comparison. Lancet 370: 1432-1442, 2007.

2 Kernan WN, Ovbiagele B, Black HR, Bravata DM, Chimowitz MI, Ezekowitz MD, Fang MC, Fisher M, Furie KL, Heck DV, Johnston SC, Kasner SE, Kittner SJ, Mitchell PH, Rich MW, Richardson D, Schwamm LH, Wilson JA, American Heart Association Stroke Council, Council on Cardiovascular and Stroke Nursing, Council on Clinical Cardiology, and Council on Peripheral Vascular Disease: Guidelines for the prevention of stroke in patients with stroke and transient ischemic attack: a guideline for healthcare professionals from the American Heart Association/American Stroke Association. Stroke 45: 2160-2236, 2014.

3 Deb P, Sharma S and Hassan KM: Pathophysiologic mechanisms of acute ischemic stroke: An overview with emphasis on therapeutic significance beyond thrombolysis. Pathophysiology 17: 197-218, 2010.

4 Yip PK, Jeng JS, Lee TK, Chang YC, Huang ZS, Ng SK and Chen RC: Subtypes of ischemic stroke. A hospital-based stroke registry in Taiwan (SCAN-IV). Stroke 28: 2507-2512, 1997.

5 Hart RG, Diener HC, Coutts SB, Easton JD, Granger CB, O'Donnell MJ, Sacco RL, Connolly SJ and Cryptogenic Stroke/ESUS International Working Group: Embolic strokes of undetermined source: the case for a new clinical construct. Lancet Neurol 13: 429-438, 2014.

6 Kistler JP: The risk of embolic stroke. Another piece of the puzzle. N Engl J Med 331: 1517-1519, 1994.

7 Sacco RL, Ellenberg JH, Mohr JP, Tatemichi TK, Hier DB, Price TR and Wolf PA: Infarcts of undetermined cause: the NINCDS Stroke Data Bank. Ann Neurol 25: 382-390. 1989.

8 Libby P: Inflammation in atherosclerosis. Nature 420: 868-874, 2002.

9 Lakhan SE, Kirchgessner A and Hofer M: Inflammatory mechanisms in ischemic stroke: therapeutic approaches. J Transl Med 7: 97-5876, 2009-7-97.

10 Whiteley W, Tseng MC and Sandercock P: Blood biomarkers in the diagnosis of ischemic stroke: a systematic review. Stroke 39: 2902-2909, 2008.

11 Pliyev BK: Activated human neutrophils rapidly release the chemotactically active D2D3 form of the urokinase-type plasminogen activator receptor (uPAR/CD87). Mol Cell Biochem 321: 111-122, 2009. 
12 Pliyev BK and Menshikov MY: Release of the soluble urokinase-type plasminogen activator receptor (suPAR) by activated neutrophils in rheumatoid arthritis. Inflammation 33: $1-9,2010$.

13 Thuno M, Macho B and Eugen-Olsen J: suPAR: the molecular crystal ball. Dis Markers 27: 157-172, 2009.

14 Eugen-Olsen J Andersen O, Linneberg A, Ladelund S, Hansen TW, Langkilde A, Petersen J, Pielak T, Möller LN, Jeppesen J, Lyngbaek S, Fenger M, Olsen MH, Hildebrandt PR, BorchJohnsen K, Jörgensen T and Haugaard SB: Circulating soluble urokinase plasminogen activator receptor predicts cancer, cardiovascular disease, diabetes and mortality in the general population. J Intern Med 268: 296-308, 2010.

15 Edsfeldt A, Nitulescu M, Grufman H, Grönberg C, Persson A, Nilsson M, Persson M, Björkbacka $\mathrm{H}$ and Goncalves I: Soluble urokinase plasminogen activator receptor is associated with inflammation in the vulnerable human atherosclerotic plaque. Stroke 43: 3305-3312, 2012.

16 Olson FJ, Thurison T, Ryndel M, Höyer-Hansen G and Fagerberg B: Soluble urokinase-type plasminogen activator receptor forms in plasma as markers of atherosclerotic plaque vulnerability. Clin Biochem 43: 124-130. 2010.

17 Sipola P, Hedman M, Onatsu J, Turpeinen A, Halinen M, Jäkälä $\mathrm{P}$ and Vanninen R: Computed tomography and echocardiography together reveal more high-risk findings than echocardiography alone in the diagnostics of stroke etiology. Cerebrovasc Dis 35: 521-530. 2013.

18 Taina M, Vanninen R, Hedman M, Jäkälä P, Kärkkäinen S, Tapiola $\mathrm{T}$ and Sipola P: Left atrial appendage volume increased in more than half of patients with cryptogenic stroke. PLoS One 2013;8:e79519.

19 Muuronen AT, Taina M, Hedman M, Marttila J, Kuusisto J, Onatsu J, Vanninen R, Jäkälä P, Sipola P and Mustonen P: Increased visceral adipose tissue as a potential risk factor in patients with embolic stroke of undetermined source (ESUS). PLoS One 2015;10:e120598.

20 Graham TP Jr., Jarmakani JM, Atwood GF and Canent RV Jr.: Right ventricular volume determinations in children. Normal values and observations with volume or pressure overload. Circulation 47: 144-153, 1973.

21 Adams HP Jr., Bendixen BH, Kappelle LJ, Biller J, Love BB, Gordon DL and Marsh EE 3rd: Classification of subtype of acute ischemic stroke. Definitions for use in a multicenter clinical trial. TOAST. Trial of Org 10172 in Acute Stroke Treatment. Stroke 24: 35-41, 1993.

22 Pepi M, Evangelista A, Nihoyannopoulos P, Flachskampf FA, Athanassopoulos G, Colonna P, Habib G, Ringelstein EB, Sicari R, Zamorano JL, Sitges M, Caso P, and European Association of Echocardiography: Recommendations for echocardiography use in the diagnosis and management of cardiac sources of embolism: European Association of Echocardiography (EAE) (a registered branch of the ESC). Eur J Echocardiogr 11: 461-476, 2010.

23 Montuori N, Visconte V, Rossi G and Ragno P: Soluble and cleaved forms of the urokinase-receptor: degradation products or active molecules?. Thromb Haemost 93: 192-198, 2005.

24 Lyngbaek S, Marott JL, Sehestedt T, Hansen TW, Olsen MH, Andersen O, Linneberg A, Haugaard SB, Eugen-Olsen J Hansen PR and Jeppesen J: Cardiovascular risk prediction in the general population with use of suPAR, CRP, and Framingham Risk Score. Int J Cardiol 167: 2904-2911, 2013.
25 Waltz DA, Fujita RM, Yang X, Natkin L, Zhuo S, Gerard CJ, Rosenberg $\mathrm{S}$ and Chapman HA: Nonproteolytic role for the urokinase receptor in cellular migration in vivo. Am J Respir Cell Mol Biol 22: 316-322, 2000.

26 Arbel Y and Strauss BH: suPAR: A cardiac biomarker with a future? Can J Cardiol 31: 1223-1224, 2015.

27 Backes Y, van der Sluijs KF, Mackie DP, Tacke F, Koch A, Tenhunen JJ and Schultz MJ: Usefulness of suPAR as a biological marker in patients with systemic inflammation or infection: a systematic review. Intensive Care Med 38: 1418-1428, 2012.

28 Hodges GW, Bang CN, Wachtell K, Eugen-Olsen J and Jeppesen JL: suPAR: A New Biomarker for Cardiovascular Disease?. Can J Cardiol 31: 1293-1302, 2015.

29 Persson M, Östling G, Smith G, Hamrefors V, Melander O, Hedblad B and Engström G: Soluble urokinase plasminogen activator receptor: a risk factor for carotid plaque, stroke, and coronary artery disease. Stroke 45: 18-23, 2014.

30 Pantoni L: Cerebral small vessel disease: from pathogenesis and clinical characteristics to therapeutic challenges. Lancet Neurol 9: 689-701, 2010.

31 Engström G, Zöller B, Svensson PJ, Melander O and Persson M: Soluble urokinase plasminogen activator receptor and incidence of venous thromboembolism. Thromb Haemost 115: 657-662, 2016.

32 Eapen DJ, Manocha P, Ghasemzedah N, Patel RS, Al Kassem H, Hammadah M, Veledar E, Le NA, Pielak T, Thorball CW, Velegraki A, Kremastinos DT, Lerakis S, Sperling L and Quyyumi AA: Soluble urokinase plasminogen activator receptor level is an independent predictor of the presence and severity of coronary artery disease and of future adverse events. J Am Heart Assoc 2014;3:e01118.

33 Kaski JC and Arrebola-Moreno AL: Inflammation and thrombosis in atrial fibrillation. Rev Esp Cardiol 64: 551-553, 2011.

34 Hirsh BJ, Copeland-Halperin RS and Halperin JL: Fibrotic atrial cardiomyopathy, atrial fibrillation, and thromboembolism: mechanistic links and clinical inferences. J Am Coll Cardiol 65: 2239-2251, 2015.

35 Suberviola B, Castellanos-Ortega A, Ruiz Ruiz A, Lopez-Hoyos M and Santibanez M: Hospital mortality prognostication in sepsis using the new biomarkers suPAR and proADM in a single determination on ICU admission. Intensive Care Med 39: 19451952,2013

36 Botha S, Fourie CM, Schutte R, Eugen-Olsen J, Pretorius R and Schutte AE: Soluble urokinase plasminogen activator receptor as a prognostic marker of all-cause and cardiovascular mortality in a black population. Int J Cardiol 184: 631-636, 2015.

37 Gozdzik W, Adamik B, Gozdzik A, Rachwalik M, Kustrzycki W and Kubler A: Unchanged plasma levels of the soluble urokinase plasminogen activator receptor in elective coronary artery bypass graft surgery patients and cardiopulmonary bypass use. PLoS One 9: e98923, 2014.

38 Lyngbaek S, Marott JL, Möller DV, Christiansen M, Iversen KK, Clemmensen PM, Eugen-Olsen J Jeppesen JL and Hansen PR: Usefulness of soluble urokinase plasminogen activator receptor to predict repeat myocardial infarction and mortality in patients with ST-segment elevation myocardial infarction undergoing primary percutaneous intervention. Am J Cardiol 110: 1756-1763, 2012.

Received January 14, 2017

Revised February 26, 2017

Accepted March 1, 2017 